\title{
Amine metabolites in the cerebrospinal fluid of patients with disseminated sclerosis
}

\author{
L. E. CLAVERIA ${ }^{1}$, G. CURZON, M. J. G. HARRISON ${ }^{2}$, \\ AND B. D. KANTAMANENI
}

From the Institute of Neurology, Queen Square, London

SYNOPSIS Mean homovanillic acid and 5-hydroxyindoleacetic acid concentrations were significantly low in the lumbar CSF of a group of patients with disseminated sclerosis (DS) who were severely disabled but not in the CSF of a less severely restricted group with DS. CSF concentrations were also low in a group of patients with superior cerebellar peduncular tremor due to DS and in a single patient with a similar tremor associated with a post-traumatic brain-stem lesion. The interpretation of abnormal CSF amine metabolite concentrations is discussed in the light of these findings.

The finding of abnormally low concentrations of dopamine in the brains of subjects with Parkinson's disease (Ehringer and Hornykiewicz, 1960) and the marked therapeutic effect in this condition of L-dopa, the precursor of dopamine, has encouraged the investigation of brain amine metabolism in other neurological disorders. In particular, the concentrations of amine metabolites in the lumbar cerebrospinal fluid (CSF) are being used to provide some indication of amine turnover in the brain (Moir et al., 1970; Curzon, 1975 , review). Thus concentrations of homovanillic acid (HVA) and 5-hydroxyindoleacetic acid (5-HIAA) give some measure of turnover of brain dopamine and 5-hydroxytryptamine respectively. Low concentrations of HVA, and to a less marked degree of 5-HIAA in CSF, have been found principally in Parkinson's disease (Bernheimer et al., 1966; Olsson and Roos, 1968; Pullar et al., 1970; Godwin-Austen et al., 1971).

During a general study of CSF amine metabolites in patients with movement disorders we have found low concentrations of HVA and 5-HIAA in the CSF of patients with the severe postural tremor of the upper limbs sometimes referred to as 'Bindearm-chorea' or superior cerebellar peduncular tremor. This tremor consists of a rhythmical protraction and retraction at the shoulder, flexion and extension at the

1 Present address: Ciudad Sanitaria, 1-Octubre, Madrid, Spain. 2 Present address: Middlesex Hospital, Mortimer St., London W.1. elbow and wrist, and independent adduction and abduction movements of individual digits (Denny-Brown, 1962). Because this tremor occurs most commonly in patients with disseminated sclerosis (Charcot, 1872; Bonduelle, 1952), amine metabolite studies were also made on CSF from patients with this disease but without superior cerebellar peduncular tremor. Low amine metabolite concentrations were found in severely impaired subjects whether they exhibited the tremor or not. The implications of these findings are discussed with respect to the interpretation of amine metabolite concentrations in the CSF.

\section{PATIENTS}

Eight patients with superior cerebellar peduncular tremor were studied of whom seven had disseminated sclerosis and one had a post-traumatic brain-stem lesion. In six patients the postural tremor was bilateral and symmetrical. In one of the patients with disseminated sclerosis the tremor was unilateral and in the traumatic case there was marked asymmetry. The group was severely disabled, partly because of the incapacitating nature of the tremor itself. Of the patients with disseminated sclerosis two were largely confined to bed and four to a wheelchair. None was able to walk unaided. All cases of disseminated sclerosis showed signs of optic atrophy and cord involvement. Six had evidence of an internuclear ophthalmoplegia.

Two groups of patients with disseminated sclerosis but without evidence of postural tremor were studied. 
The first group contained 10 patients who were all less severely disabled than the patients with superior cerebellar peduncular tremor, and none was confined to a wheelchair. Two of these patients had a cerebellar intention tremor. Three showed optic atrophy and four had evidence of brain-stem lesions. All had signs of a spinal cord lesion. A second group contained nine chronic and severely disabled patients without superior cerebellar peduncular tremor. All showed evidence of brain-stem and spinal cord lesions. Seven had evidence of optic atrophy and seven had evidence of cerebellar lesions.

A control group consisted of 10 patients with miscellaneous neurological disorders who were all normally mobile and without evidence of any movement disorder. No subject studied had been recently treated with drugs known to influence brain amine metabolism.

\section{METHODS}

CSF was taken by lumbar puncture and stored at $-20^{\circ} \mathrm{C}$ until determinations of HVA and 5-HIAA were performed (Godwin-Austen et al., 1971).

\section{RESULTS}

The biochemical data are shown in the Figure and summarized in the Table. Mean concentrations of HVA and 5-HIAA in the CSF of subjects with superior cerebellar peduncular tremor and with severe disseminated sclerosis are simi-

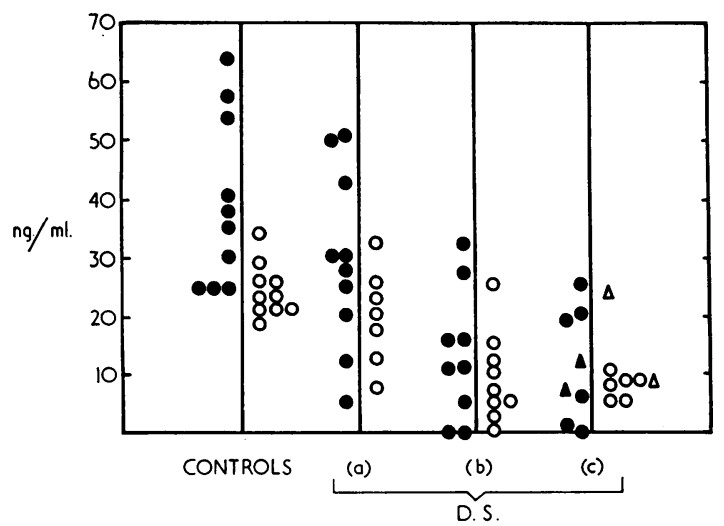

FIGURE Lumbar CSF amine metabolite concentrations of three groups of patients with disseminated sclerosis; (a) mobile, (b) immobile, (c) with cerebellar peduncular tremor. Results on a control group of miscellaneous neurological patients are also shown. : HVA. $\bigcirc:$ 5-HIAA. $\triangle, \triangle$ : values for the atypical subjects described in the text.
TABLE

LUMBAR CSF HVA AND 5-HIAA CONCENTRATIONS IN DISSEMINATED SCLEROSIS

\begin{tabular}{lrccc}
\hline & Number & $\begin{array}{c}\text { Age } \\
(y r)\end{array}$ & $\begin{array}{c}H V A \\
(n g / m l)\end{array}$ & $\begin{array}{c}5-H I A A \\
(n g / m l)\end{array}$ \\
\hline $\begin{array}{l}\text { Disseminated sclerosis } \\
\text { Mobile }\end{array}$ & 10 & $41 \pm 12$ & $29 \pm 15$ & $20 \pm 6$ \\
$\begin{array}{l}\text { Immobile } \\
\text { Cerebellar peduncular } \\
\text { tremor }\end{array}$ & 9 & $49 \pm 10$ & $14 \pm 10^{*}$ & $9 \pm 8^{*}$ \\
$\begin{array}{l}\text { Miscellaneous neuro- } \\
\text { logical patients }\end{array}$ & 6 & $39 \pm 6$ & $12 \pm 11^{*}$ & $8 \pm 2^{*}$ \\
\hline
\end{tabular}

Values given $\pm 1 \mathrm{SD}$.

* Less than values for miscellaneous neurological patients, $P<0.001$.

lar and are significantly below those of the miscellaneous control group. Values for the less severely impaired subjects with disseminated sclerosis occupied an intermediate range but means were not significantly different from those of the control group. Determinations on CSFs of the patient with unilateral cerebellar peduncular tremor and of the post traumatic patient are not included in the means but are shown in the Figure. Both had low HVA concentrations in the CSF. It is of interest that the patient with unilateral symptoms had normal 5-HIAA content.

Although there was little overlap between values found for subjects with cerebellar peduncular or severe disseminated sclerosis and those for the miscellaneous control group, overlaps with the group with less severe disseminated sclerosis were more marked (Figure).

HVA was undetectable in one patient with superior cerebellar peduncular tremor and remained so after treatment for five days with 100 $\mathrm{mg} /$ day of the amine releaser tetrabenazine. The CSF HVA concentration of another patient with this condition rose from $6 \mathrm{ng} / \mathrm{ml}$ to $166 \mathrm{ng} / \mathrm{ml}$ when given $4 \mathrm{~g} \mathrm{~L}$-dopa/day. This increase is comparable with increases of CSF HVA after administration of dopa to subjects with Parkinsonism (Godwin-Austen et al., 1971).

\section{DISCUSSION}

It has thus been shown that mean concentrations of HVA in lumbar CSF were low in patients with superior cerebellar peduncle tremor and with severe disseminated sclerosis. Concentrations 
were similar to those found in this laboratory in Parkinsonism (Godwin-Austen et al., 1971). The 5-HIAA concentrations are somewhat below those in Parkinsonism. Superficially, these results suggest impaired brain amine metabolism. However, while in Parkinson's disease the finding of low HVA concentration in CSF was consistent with earlier reports of low dopamine concentration in the basal ganglia at necropsy, lesions in these nuclei are not typical of disseminated sclerosis and brain dopamine determinations have not been reported. Abnormal CSF findings can result not only from abnormal brain amine metabolism but also from abnormality of the active transport of amine metabolites from CSF or brain to blood. For example, defective transport to blood leading to high CSF levels of HVA and 5-HIAA has been described (Bowers, 1969). Also the rate of mixing of the ventricular CSF (into which brain amine metabolites are secreted) with the contents of the lumbar sac may influence amine metabolite concentrations therein. It is of interest that HVA and 5-HIAA levels in the lumbar CSF both increase after a four hour period of increased motor activity (Post et al., 1973). The extent to which such changes relate to increased mixing or increased amine turnover is unclear, although rat brain HVA does increase after increased activity (Bliss and Ailion, 1971). These findings do imply, however, that severely altered mobility might well lead to secondary alteration of amine metabolite concentration in lumbar CSF. Postmortem determinations of brain amines would help to clarify their role in disseminated sclerosis.

Very recently, Sonninen et al. (1973) have also reported low amine metabolite concentrations in the CSF of chronic and bedridden patients with disseminated sclerosis, although findings were less striking than those noted here. Probenecid was used to prevent transport of acidic amine metabolites from CSF to blood in an attempt to determine whether the low values were due to an abnormality of synthesis or of transport. Results on patients with disseminated sclerosis were proportionately as low as in the absence of probenecid but were no longer statistically significant, possibly because of the relative increase of standard error which is often found to follow use of the probenecid technique.

Results reported here and evidence of low amine metabolite concentrations in the CSF of patients with progressive supranuclear palsy, Shy-Drager disease, rigid Huntington's chorea, and motor neurone disease (Brody et al., 1970; Mendell et al., 1970, 1971; Curzon et al., 1972; Curzon, 1973) all indicate that such findings are not pathognomic of Parkinson's disease or of disease confined clinically to the extrapyramidal system.

D.B.K. was supported by a grant from the National Fund for Research into Crippling Diseases. We thank Dr M. A. Tudor, Royal Home and Hospital for Incurables, for access to patients.

\section{REFERENCES}

Bernheimer, H., Birkmayer, W., and Hornykiewicz, O. (1966). Homovanillinsäure in Liquor cerebrospinalis: Untersuchungen beim Parkinson-Syndrom und anderen Erkrankungen des ZNS. Wiener klinische Wochenschrift, 78, 417-419.

Bliss, E. L., and Ailion, J. (1971). Relationship of stress and activity to brain dopamine and homovanillic acid. Life Sciences, 10 Part 1, 1161-1169.

Bonduelle, M. (1952). Les tremblements; étude séméiologique et nosologique. Revue Neurologique, 86, 567-583.

Bowers, M. B. (1969). Deficient transport mechanism for the removal of acid monoamine metabolites from cerebrospinal fluid. Brain Research, 15, 522-524.

Brody, J. A., Chase, T. N., and Gordon, E. K. (1970). Depressed monoamine catabolite levels in cerebrospinal fluid of patients with parkinsonism dementia of Guam. New England Journal of Medicine, 282, 947-950.

Charcot, J. M. (1872). Leçons sur les Maladies du System Nerveux faites à la Salpêtrière. Vol. 1. Delahaye: Paris.

Curzon, G. (1973). Involuntary movements other than parkinsonism: biochemical aspects. Proceedings of the Royal Society of Medicine, 66, 873-876.

Curzon, G. (1975). Amine metabolites in cerebrospinal fluid in extrapyramidal disease and the effect of therapy upon them. In International Encyclopaedia of Pharmacology and Therapeutics. Section 25 (Pharmacology of the Extrapyramidal system). Edited by O. Hornykiewicz. Pergamon Press: Oxford. (In press.)

Curzon, G., Gumpert, J., and Sharpe, D. (1972). Amine metabolites in the cerebrospinal fluid in Huntington's Chorea. Journal of Neurology, Neurosurgery, and Psychiatry, 35, 514-519.

Ehringer, H., and Hornykiewicz, O. (1960). Verteilung von Noradrenalin und Dopamin (3-Hydroxytyramin) im Gehirn des Menschen und ihr Verhalten bei Erkrankungen des extrapyramidalen Systems. Klinische Wochenschrifte, 38, 1236-1239.

Godwin-Austen, R. B., Kantamaneni, B. D., and Curzon, G. (1971). Comparison of benefit from L-dopa in Parkinsonism with increase of amine metabolites in the CSF. Journal of Neurology, Neurosurgery, and Psychiatry, 34, 219-223.

Mendell, J. R., Chase, T. N., and Engel, W. K. (1970). Modification by L-dopa of a case of progressive supranuclear palsy. Lancet, 1, 593-594.

Mendell, J. R., Chase, T. N., and Engel, W. K. (1971). 
Amyotrophic lateral sclerosis. Archives of Neurology, 25, 320-325.

Moir, A. T. B., Ashcroft, G. W., Crawford, T. B. B., Eccleston, D., and Guldberg, H. C. (1970). Cerebral metabolites in cerebrospinal fluid as a biochemical approach to the brain. Brain, 93, 357-368.

Olsson, R., and Roos, B.-E. (1968). Concentrations of 5-hydroxyindoleacetic acid and homovanillic acid in the cerebrospinal fluid after treatment with probenecid in patients with Parkinson's disease. Nature, 219, 502-503.

Post, R. M., Kotin, J., Goodwin, F. K., and Gordon, E. K.
(1973). Psychomotor activity and cerebrospinal fluid amine metabolites in affective illness. American Journal of Psychiatry, 130, 67-72.

Pullar, I. A., Weddell, J. M., Ahmed, R., and Gillingham, F. J. (1970). Phenolic acid concentrations in the lumbar cerebrospinal fluid of Parkinsonian patients treated with L-dopa. Journal of Neurology, Neurosurgery, and Psychiatry, 33, 851-857.

Sonninen, V., Riekkinen, P., and Rinne, U. K. (1973). Acid monoamine metabolites in cerebrospinal fluid in multiple sclerosis. Neurology (Minneap.), 23, 760-763. 